\title{
1 Effect of Solar Radiation on Suspension Bridge 2 Performance
}

3 Robert Westgate'; Ki-Young Koo² ${ }^{2}$; and James Brownjohn ${ }^{3}$.

\section{Abstract}

6 Observations on a UK suspension bridge show that thermal expansion and contraction cycles

7 do not follow simple linear relationships with a single temperature value, and that time lag

8 and temperature distribution can be significant factors. In this investigation these effects are

9 explored by simulating the transient thermal and quasi-static response of the Tamar Bridge

10 with separate finite element models of the bridge and suspension cables. Thermal loads are

11 determined by calculated solar radiation intensities and temperature data from the bridge monitoring system. Since cloud cover plays an important role to the levels of solar radiation, cloud coverage was estimated indirectly using monitored temperature differences between the top and bottom of the suspended structure. The results demonstrated that peak temperatures of the suspended structure and cables occurred at different times. The lag was caused by differing material properties and the surfaces' ability to absorb and lose heat. Transient phenomena manifest in the structural responses such as the tower sway.

${ }^{1}$ Research associate, Department of Civil and Structural Engineering, the University of Sheffield, Sheffield, United Kingdom, S1 3JD. Email: rjwestgate@ gmail.com

${ }^{2}$ Lecturer, College of Engineering, Mathematics and Physical Sciences, University of Exeter, Exeter, United Kingdom, EX4 4QF. Email: dr.ki.koo@gmail.com

3Professor of Structural Dynamics, College of Engineering, Mathematics and Physical Sciences, University of Exeter, Exeter, United Kingdom, EX4 4QF (corresponding author). Email: j.brownjohn@exeter.ac.uk 


\section{Subject headings}

cable-stayed bridges; solar radiation; steel; structural health monitoring; suspension bridges; temperature effects

\section{Introduction}

One of the many purposes of a Structural Health Monitoring (SHM) system is to look for anomalies in monitored performance data that may signal a change in the structure's condition. A major challenge with this approach is data normalisation, filtering out the contributions of varying operational and environmental loading conditions to reveal underlying effects of structural changes (Sohn 2007). For long span bridges two of the major factors in performance are air temperature and solar radiation, resulting in structural temperature variations with time and location. These in turn cause the structure to expand and deform (Ding and Li 2011b; Ni et al. 2007), as well as drive changes in the material properties, primarily stiffness (Peeters and De Roeck 2001).

While data-driven approaches to the data normalisation problem fit mathematical models to recorded deformations and temperatures (Cross et al. 2011), the models cannot recreate the full range of structural responses observed. There is a wider range of possible responses on complex structures such as suspension bridges; variations in structural temperatures produce a variety of deformed configurations. Some of these responses are caused by transient effects and are dependent on how rapidly the structure warms up and cools down.

Different regimes of thermal loading will also be experienced through an annual cycle: solar radiation intensities and directions differ seasonally, and air temperatures are lower during winter than in summer. As a result the structure behaves differently throughout the year, such as thermal displacements of the bridge and changes in its modal properties. 
42 These seasonal structural responses have only been observed through a results collected from long-term monitoring systems (Ding and Li 2011a; Liu et al. 2009; Miao et al. 2011; Ni et al. 2007; Xu et al. 2010; Zhou et al. 2010) and not via mathematical models, to the authors' knowledge.

Before transient thermal response mechanisms were studied closely by structural engineers, temperature effects were represented through a series of empirical equations (Churchward and Sokal 1981; Hirst 1984), using thermal loads as variables. However their application is limited to bridges of a similar construction and climate to those studied. Ho and Liu (1989) were among the first to explore transient thermal loads. They used 207 days of data monitored from a concrete bridge in Hong Kong and calibrated a simulated response provided by a one dimensional finite difference model. There are a few other studies that have considered the thermal response of a concrete structure (Minhoto et al. 2005; Moorty and Roeder 1992; Xia et al. 2011). These investigations commented on the temperature gradient through the structure's depth, and attributed thermal lag between the top and bottom faces to the shading of the structure and the low thermal conductivity of concrete.

Several studies have observed the thermal response of steel structures. Tong et al. (2001, 2002) performed sensitivity studies on a numerical model to determine the material properties of a steel box section and observed how the temperature gradient was affected by various beam profiles. Cao et al. (2010) identified a temperature gradient through the deck of the Zhanjiang Bay (cable stay) Bridge from results collected by their monitoring system. The effect of heat flow on suspension bridge spans and abutment has been previously studied by Xia et al. (2013). Their investigation uses results collected from Tsing-Ma Bridge during a single day, both from monitored data and finite element (FE) models.

As remarked in the Tsing-Ma Bridge investigation, from the thermal response viewpoint a suspension bridge is a much more complex system than a bridge that is only 
supported on its underside by a truss or girder. The various members have different thermal responses due to their various material properties, shape and size, as well as their location in the structure. Structural responses are also coupled, making it difficult to link specific causes and effects: cable slackening could be caused by thermal expansion or relative movement between deck and tower(s). Multiple structural arrangements further complicate analysis due to structural redundancy and complex shading.

In this investigation time dependent thermal effects are studied by examining longterm monitored responses and FE transient analyses from the Tamar Bridge, a suspension bridge with additional stay cables in Southwest England. Transient thermal effects are analysed for 5 days in each of the 12 months of a single year, rather than for a single day.

This approach should cover seasonal effects on the thermal response, resulting from differing ranges of air temperature and applied solar radiation.

\section{Application to the Tamar Bridge}

\section{Tamar Bridge}

The Tamar Bridge was opened in 1961 and forms the main transport link between Plymouth and Saltash. The bridge has a $335 \mathrm{~m}$ main span and two $114 \mathrm{~m}$ side spans, with the deck located halfway up the $73.2 \mathrm{~m}$ tall concrete towers and supported by a pair of $38 \mathrm{~cm}$ diameter suspension cables, each consisting of thirty-one $60 \mathrm{~mm}$ diameter locked-coil steel ropes. A strengthening and widening exercise was completed in 2001, replacing the original concrete deck with a lighter orthotropic steel deck. Furthermore two additional lanes were cantilevered from the $4.9 \mathrm{~m}$ deep stiffening truss to increase the width of the bridge from $15.2 \mathrm{~m}$ to $27.2 \mathrm{~m}$. These were originally intended to carry traffic during the deck replacement but now serve to provide an additional vehicle lane on one side of the bridge and a footpath and cycleway on the other. Nine pairs of stay cables were also installed as part of the scheme and are arranged 
as shown in Figure 1. Eight pairs $(\mathrm{S} 3, \mathrm{~S} 1 \ldots \mathrm{P} 3)$ are attached from the tops of the main towers to either the base of the side towers or the truss. The ninth pair of stay cables is attached to the underside of the truss.

The bridge span is able to expand longitudinally due to an expansion gap near the Saltash main towers. Lateral sway of the truss between the main towers is restrained by a pair of thrust bearings, and pairs of rockers at the end of the truss are seated on ledges at the towers to provide vertical restraint to the ends of the spans.

\section{Monitoring systems}

The SHM research on the Tamar Bridge has made extensive use of environment and response data provided by a range of structural monitoring systems. The following section describes the systems used in the studies for this paper.

\section{Fugro Monitoring System}

Alongside the strengthening and widening scheme, a monitoring system was installed by Fugro Structural Monitoring, allowing the bridge operators to keep track of the bridge's performance. The system consists of 90 data channels from a wide variety of sensors that are detailed in full by Koo et al. (2012), but only the thermogauges are relevant to the investigation in this paper. The locations of these sensors are shown in Figure 1.

Six thermogauges are located at midspan that measure the temperature of the deck and the truss: four surround one of the lower spanwise members in the truss, one measures the deck temperature and another measures the temperature of the air underneath the deck. Both of the side spans have a single thermogauge attached to the underside of the deck, as well. Since the system is a retrofit, the sensor that determines the suspension cable temperature is attached to the northern cable wrapping. The local air temperature is acquired from a sensor attached to a hanger near the Saltash tower. The sensors on the cable and 
suspended structure consist of platinum resistance thermometers mounted on stainless steel shim, which is held against the structure by an adhesive. The air temperature sensor is a ceramic element contained within a stainless steel sheath, protected by a radiation shield.

The data from the Fugro system are stored as a comma-delimited ASCII file for each day and are stored on a robust 'Toughbook' laptop located in a closed off control chamber. The Toughbook is connected to the internet via an ADSL router, so any changes to the configuration of the sensors can be made by remote connection (Teamviewer or Remote Desktop). The Toughbook transfers the data files every 24 hours via FTP to a server at the University of Exeter, which runs MATLAB scripts to upload and process the recent measurements, and are subsequently added to a MySQL database.

\section{Webcam}

Two webcams are positioned on the top of the Plymouth tower; one pointed towards the Plymouth side span, the other directed towards the main span. Both webcams capture an image of their side of the bridge every 10 minutes to provide visual information of the weather and traffic activity. Similar to the data from the Fugro system, these images are saved to the Toughbook then transferred to a server by FTP.

\section{Quasi-static displacements}

In order to track the structural movements of the bridge, a Total Positioning System (TPS) with a Robotic Total Station (RTS) and 15 reflectors was installed in September 2009 (Koo et al. 2010). The RTS is an innovation of the project, since it is an automated system that locates the reflectors in a cycle within a ten minute duration, repeated at intervals of approximately 30 minutes. The RTS provides reflector coordinates in the three axes that characterise the deformation of the bridge. Reflectors are distributed evenly along the southern cantilevered lane of the bridge as well as on the saddle and deck levels of the towers; their locations have 
also been represented in Figure 1.

The RTS unit is a Leica TCA1201, which is designed for measuring at ranges exceeding $8 \mathrm{~km}$ under ideal weather conditions, and has an accuracy of $2 \mathrm{~mm}$ plus $2 \mathrm{~mm}$ per kilometre when measuring distance. For the Tamar Bridge the farthest reflector is $650 \mathrm{~m}$ from the RTS, so the error over this distance may be up to $3.3 \mathrm{~mm}$ ( $2 \mathrm{~mm}$ plus $1.3 \mathrm{~mm})$. The accuracy of the theodolite component of the RTS is 1 arc-second leading to $3.2 \mathrm{~mm}$ error in the vertical and lateral directions. The RTS is capable of working reliably within the glass housing used for weather protection but there are occasions when poor weather conditions such as morning mist compromise the operation of the system due to light refraction in water droplets. Otherwise the measurements have been reliable.

GeoMos Monitor software is installed on the Toughbook to adjust control settings and the periodic measurements of the TPS runs. The software stores the measurements from the RTS in a Microsoft Structured Query Language (MS SQL) database. Subsequently a MATLAB script on the university server reads the data from the Toughbook database and writes it to the MySQL database on the server.

One of the pioneering abilities of the SHM system is that the real-time performance of bridge can be viewed online from anywhere in the world with a web browser (Koo et al. 2011). This is made possible by a web interface that has access to the MySQL database at the university, which provides the capability of viewing time series of the bridge and weather behaviour and making direct comparisons between two or more sets of data. The web interface has enabled easy manipulation of graphs online to consider how the thermal performance of monitored members may be interacting with each other over long periods of time. 


\section{Heat transfer analysis}

163 The wealth of monitored temperature data and webcam images collected from the bridge

164 enable observations on the heat and cloud conditions for each day. This information provides

165 an insight on the structure's ability to gain and lose heat, which can be used calibrate mathematical models so that they replicate monitored behaviour. The equations in the following subsection dictate how heat is transferred within the system.

\section{Heat transfer equations}

The temperature field $T$ of a cross section at time $t$ may be expressed by Poisson equation models for the 3D transient heat flow process (Minhoto et al. 2005), representing the heat travelling through a homogenous solid via conduction:

$$
k\left(\frac{\partial^{2} T}{\partial x^{2}}+\frac{\partial^{2} T}{\partial y^{2}}+\frac{\partial^{2} T}{\partial z^{2}}\right)=\rho c \frac{\partial T}{\partial t}
$$

172 where $x, y$ and $z$ are Cartesian coordinates on the bridge, $k$ the thermal conductivity, $\rho$ the density and $c$ the specific heat capacity of the material.

At a boundary the heat flow in a direction normal to the surface is expressed as

$$
k \frac{\partial T}{\partial n}+q=0
$$

where $n$ is the normal to the boundary's surface and $q$ is the heat flow at the boundary. For a

176 bridge surface $q$ consists of convection $q_{c}$, thermal radiation emitted from the surface $q_{r}$ and 177 solar irradiation $q_{j}$ (Branco and Mendes 1993; Elbadry and Ghali 1983):

$$
q=q_{c}+q_{r}+q_{j}
$$




$$
q_{c}=h\left(T_{\text {sur }}-T_{\text {air }}\right)
$$

179 where $T_{\text {sur }}$ and $T_{\text {air }}$ are the surface and air temperature respectively, and $h$ the convection coefficient. The heat radiated from the surface $q_{r}$ is dependent on its emissivity coefficient $\varepsilon$

$$
q_{r}=\varepsilon \sigma T^{4}
$$

182

where $\sigma$ is the Stefan-Boltzmann constant, which is the total energy radiated from a black body per unit surface area, per unit time.

Finally the amount of solar radiation absorbed by a bridge surface (Minhoto et al. 2005; Xia et al. 2013) is

$$
q_{j}=-\alpha J_{0}
$$

where $\alpha$ is the solar radiation absorption coefficient of the surface material (between 0 and 1), and $J_{0}$ is the total daily irradiance on the bridge surface. An estimate for the solar radiation for any day of the year was calculated using the Johnson-Woodward model (Johnson et al. 1995; Woodward et al. 2001), which was originally intended for agricultural purposes. The model was chosen due to recommendation by Rivington et al. (2005) and for its simplicity. The formulae used to calculate the radiation are found in the Appendix.

\section{Estimation of cloud cover}

In order to approximate the intensity of solar radiation on the deck, values for the cloud cover at the observed time are required. Cloud-cover has not been well studied in the bridge community, but it affects the amount of solar radiation the surface of the bridge deck receives directly. While data were available from Plymouth Airport (Roborough), the data were 
inadequate, as elaborated later. Thus an alternate method was developed with the aim that FE simulated structural temperatures would be similar to the monitored values.

Two dates with varying cloud levels were chosen to gauge upper and lower bounds for the calculated cloud cover values. Webcam images contain several features that indicate the degree of cloud cover: images with cloudier skies are greyer and less bright than images on clear days. Shadows also have crisp edges when they are under direct sunlight. In future, image processing software might be trained to identify such features. For the investigation the lower bound was January $10^{\text {th }}, 2010$, when the bridge was covered by fog for the duration of the day. The upper bound was July $8^{\text {th }}, 2010$, as the images indicated a clear day throughout the morning.

Another readily available indicator for the amount of cloud cover is the comparison of temperature data from two or more sensors on the structure, such as the time series in Figure 2. On cloudy days like January $10^{\text {th }} 2010$ (top) the temperature of the deck, cables and truss is very similar throughout the day, since the bridge is mostly warmed by the air. On clear days such as July $8^{\text {th }} 2010$ (bottom) the deck temperature at midday is much higher than the temperature on the truss. The difference in temperature between the deck and the truss is larger on clear days compared to cloudier days within the same month. For the Tamar Bridge the warmest monitored parts of the structure are the deck and the suspension cables, since they are in direct sunlight and gain heat from solar radiation. The truss, however, is often the coolest part since it is shaded by the cantilevered lanes. The supported structure is also made of steel, so it loses heat stored within its thermal mass during the same day.

Thus $\Delta T_{t}$, the difference between the temperature of the suspension cable and truss at time $t$, was used to approximate the cloud cover levels. Use of the deck temperature was considered but deck temperature occasionally fell below that of the truss and would produce less reliable results than the suspension cable. 

summer compared to winter, regardless of the cloud cover level. Both the diurnal and seasonal behaviours already feature in the Johnson-Woodward model as sinusoids (see Equations A.4, A.8 and A.12 in the Appendix). Therefore the value of $\Delta T_{t}$ requires modification so that it is only linked to thermal behaviour resulting from cloud cover, and removes behaviour linked to the rise and fall of the sun. behaviour but the resulting curves formed acute peaks at midday, when rounded curves were desirable to provide no sudden changes of cloud cover. It was found that using a simple moving average over a 21 hour interval $(r+1)$ would remove the daily fluctuations to an acceptable degree:

$$
\Delta T_{t}^{\prime}=\frac{\Delta T_{t-r / 2}+\cdots+\Delta T_{t}+\cdots+\Delta T_{t+r / 2}}{(r+1)}
$$

where $\Delta T^{\prime}{ }_{t}$ is the modified value of $\Delta T_{t}$. The resultant peaks in the smoothed data appear at similar times as clear spells in several webcam images. equivalent cloud cover factor, $f_{c c}$. This was also performed over a roaming interval, with the data normalised to the maximum and minimum values within a specified range. This method assumes that within the interval there is at least one instance where the sky is completely cloudless $\left(f_{c c}=0\right)$, and one instance where the sky is totally covered in cloud $\left(f_{c c}=1\right)$.

$$
f_{c c, t}=\frac{\Delta T_{t}^{\prime}-\mathbb{T}_{\min }}{\mathbb{T}_{\max }-\mathbb{T}_{\min }}
$$

240 where $f_{c c, t}$ is the predicted cloud cover at time $t$, and $\mathbb{T}_{\min }$ and $\mathbb{T}_{\max }$ are the minimum and maximum $\Delta T_{t}{ }^{\prime}$ within the observed interval: 


$$
\begin{aligned}
& \mathbb{T}_{\min }=\min \left[\Delta T_{t-s / 2}^{\prime} ; \cdots ; \Delta T_{t}^{\prime} \cdots ; \Delta T_{t+s / 2}^{\prime}\right] \\
& \mathbb{T}_{\max }=\max \left[\Delta T_{t-s / 2}^{\prime} ; \cdots ; \Delta T_{t}^{\prime} \cdots ; \Delta T_{t+s / 2}^{\prime}\right]
\end{aligned}
$$

By testing various sizes of an interval $s$ and comparing webcam images an interval

length of 7 weeks provided acceptable values for cloud cover for the Tamar Bridge. This interval also ensures cloud cover levels are determined on a month-by-month basis, since the temperature difference is larger during the summer than winter.

Figure 3 presents the cloud cover predicted by the method described for the two dates seen previously. These results are compared to data monitored from Plymouth Airport that were also available for use, acquired from weather information by Wolfram Mathematica 7 software. The cloud cover method produces the intended results: cloud cover factors close to 1 in the January data, and low cloud cover at midday in the July data. The data collected from Plymouth Airport on the other hand do not provide an acceptable representation of the cloud cover seen in the webcam images. Apart from having just three absolute values $(0.25,0.5$ and 0.9) they may also be incorrect for the Tamar Bridge since the two locations are $6.9 \mathrm{~km}$ apart, and the airport is $142 \mathrm{~m}$ above sea level. The airport data for January $10^{\text {th }}$ suggests times when there was little cloud, while the webcam images show the bridge, which is at sea level, was surrounded by fog for the whole day. Hence the developed cloud cover method was used when monitored results were available. While the levels of cloud cover may not be correct during the late evening/early morning period, these periods generally occur overnight, so would have a very limited effect on the solar radiation calculations.

The method described here is an innovation of the project, since it uses monitored temperature data in order to acquire a value for cloud cover that is otherwise difficult to quantify. The values determined from this method have been reasonable for further use in the solar radiation calculations. Temperature data also requires less memory storage than 
webcam images, which allows for more opportunities of gaining further thermal information by installing additional thermogauges around the structure.

\section{Applied solar radiation}

267 Using the temperatures monitored from the actual structure, approximate cloud cover levels and the method described in the Appendix, estimates for the solar radiation applied to the bridge were now available.

The radiation loads were applied to the orthotropic deck and tower faces in the FE model, which were also subject to air convection and surface radiation. Due to the complex arrangement of the truss, radiation effects were not applied to the underside of the bridge. However on simpler structures shading could be approached in a similar way as Liu et al. (2012).

\section{Application to the finite element (FE) model}

An FE model was developed as part of our investigations on the Tamar Bridge to assist with interpretations of behaviour observed in the monitored data (Westgate and Brownjohn 2010). The model was developed in ANSYS 12.1, which allows for the option of performing thermal and structural analyses on the same model. A multi-physics analysis was applied to combine the two sets of results: first the problem is solved via a thermal analysis to determine the structure's temperature and thermal stresses, then the results were transferred as an additional load for a structural analysis.

\section{FE model details}

The 3D FE model of the Tamar Bridge was developed from a combination of shell and line elements, shown in Figure 4 (top). For structural analyses, the truss members were modelled with either BEAM4 or BEAM44 three dimensional elastic beam elements. The cables and hangers were modelled with LINK10 spar elements with the "tension only" option selected. 
The plate elements that composed the deck and tower sides were modelled with SHELL63 elastic shell elements. The stiffness caused by friction at the bearings at the Saltash expansion gap and the ends of the bridge was modelled by a series of spring elements. The properties of the FE model were calibrated using modal properties (frequency and mode shape) established during an ambient vibration survey (Brownjohn and Carden 2008).

For thermal analyses the structural element types were replaced with thermal counterparts that are able to conduct heat: 3D beam elements in the model used LINK33 and the plate elements used SHELL57. Convection and radiation effects were applied to plate elements such as the concrete towers and the deck surface by overlaying two layers of SURF151 elements, shown in Figure 4 (bottom).

One limitation is the inability to apply radiation to line elements such as the suspension cables, since the elements in the model do not have a surface area defined. There are also far too many different beam sections, each receiving different amounts of shade, to perform individual radiation analyses. Instead the monitored truss temperatures were applied to the nodes on the lower stringers of the truss as they directly represent its thermal response. Since the suspension cable is one of the most important structural elements for determining the bridge configuration, it was felt that a complete solar radiation analysis should include a thermal simulation through a section of the cable. This model was made up of PLANE55 elements: 2D thermal solid elements with 3 or 4 nodes. Neighbouring nodes in the models, such as within $1 \mathrm{~cm}$ of the wrap or adjacent wires, were thermally coupled to transfer heat between the wires and the wrap.

\section{Calibration of thermal properties}

The next stage was to ensure that the response from the FE model provides a good match with results found during monitoring. The thermal response of the FE model was calibrated to daily samples of temperature data recorded from the actual structure to adjust unknown 
thermal properties such as the absorption, emissivity and convection coefficients of the surfaces in the model. To see how the bridge responds to high and low levels of solar radiation, the two dates used previously to determine cloud cover (January $10^{\text {th }}$ and July $8^{\text {th }}$, 2010) were utilized to ensure that the peak thermal response of simulated bridge occurred at the time recorded in the monitored results, with the same temperature.

Through a series of tests it was determined that the absorption and convection coefficients were the most influential parameters governing the thermal behaviour of the structure: the convection coefficient determines the time when the peak temperature occurs, and the absorption coefficient affects the amplitude of the simulated temperature. By adjusting each variable a solution was produced where the peaks in the simulated and monitored results coincided.

The rise and fall of the monitored and simulated data was not a perfect match; during the morning on July $8^{\text {th }}$ the simulated temperatures were up to $3.8^{\circ} \mathrm{C}$ larger than temperatures monitored from the structure. These errors were attributed to wind chill, which is not accounted for within the FE model. By using the estimated cloud factors the applied radiation in the FE model would be lessened during the morning and evening periods, and the error reduced to within $2^{\circ} \mathrm{C}$, which was considered acceptable.

The thermal properties of the bridge used in the FE model are presented in Table 1, assuming a linear relationship with temperature between $-20^{\circ} \mathrm{C}$ and $100^{\circ} \mathrm{C}$. The adopted thermal conductivity of the combined asphalt and steel deck is that of the asphalt alone, since its low conductivity would determine how quickly the heat would spread. Other thermal properties were adopted from the Comité Euro-International du Béton design code (Comité Euro-International du Béton 1993) and the relevant British Standards (British Standards Institution 2005a; b).

The emissivity, absorption and convection coefficients used for steel in this 
investigation are similar to those used by Elbadry and Ghali (1983) and Branco and Mendes (1993), so by comparison the properties used in this study should replicate the thermal response of the material. In reality these coefficients are not likely to be constant across the bridge. Certain locations on the bridge may fade since they are prone to weathering, which affects their surfaces ability to absorb and emit heat. There are also irregularities within the members and their coating. Since the investigation is observing the bridge's overall performance, these localised distortions would provide little error to the produced results. However the materials used for the bridge's construction in 1961 are subject to differing manufacturing methods, and would have distorted with age. For this reason the materials are not the same for members added at a later date, such as during the 2001 strengthening and widening exercise. This would be a likely source of error. In this investigation the effect should be lessened since the newer members are typically found on surface elements in the central lanes and the cantilever lanes, and were subject to surface loads in the thermal analysis. These members were treated differently than older steel members, which are the line elements in the truss.

\section{Diurnal and seasonal variations of thermal loading and structural response}

Assuming the FE model of the suspension cable and the full bridge provide an accurate representation of the bridge through a transient heat analysis, they can be used to simulate the bridge performance for longer periods and a variety of thermal conditions. In order to determine how the bridge responds to time dependent thermal loading throughout the year, sixty days of monitored performance data were chosen for a detailed study.

\section{Time series of bridge temperature}

Five consecutive days $\left(10^{\text {th }}\right.$ to the $\left.14^{\text {th }}\right)$ were chosen for each of the 12 months in 2010 to represent variations that occur seasonally, rather than just diurnally. Like the calibration tests, 
these periods include effects of solar radiation and air convection, plus monitored truss temperatures.

The simulated cable temperatures from the FE model in Figure 5 (top) demonstrate a good fit with the monitored results with occasional anomalies. There are errors between the simulated and monitored results that tend to occur around midday during October, when the monitored cable temperatures are much higher than the simulated temperatures. Observations at night provide a close match, which indicates that the simulated solar radiation was too high for this period. Overall the median error from the deck temperatures is $0.59^{\circ} \mathrm{C}$ and the monitored and simulated data sets have a correlation coefficient of 0.968 , which the researchers view as a satisfactory match.

Compared to the cable results, Figure 5 (middle) also demonstrates a good agreement between the results monitored from the bridge and the simulated temperatures from the FE model. Errors generally occur when the peak daily temperatures do not match the monitored results at noon, which appears to be the same error as seen in the cable temperatures. It is also possible that monitored results may be lower than predicted due to wet conditions, when surface water absorbs heat.

Simulated temperature time series for the southern face of Plymouth tower in Figure 5 (bottom) show that their peak temperature occurs between 2 to 4 hours after the peak temperature of the deck. The tower continues to lose heat into the following morning, since the concrete of the towers loses heat to convection and heat radiation more slowly compared to the steel elements. While there is no monitored data available, since there are no thermogauges currently attached to the towers, the FE simulated behaviour is similar to the monitored thermal response of the Zhang-Jiang Bay Bridge's concrete towers (Cao et al. 2010), for which the same conclusion was drawn about the material properties. 


\section{Time series of quasi-static displacement of the suspended structure}

387 Figure 6 presents the structural displacement time series for 10 days of observed data: 5 days taken during July and the remaining 5 during October. The time series compare the results predicted from the FE analysis at midspan (CG062 in Figure 1) to the monitored results. Both sets of data show larger movements of the deck when there are larger variations in deck temperature, as expected. For the most part the simulated time series overlap the monitored results, providing a correlation coefficient of 0.970 for expansion, and 0.958 for vertical deflection. The FE results tend to overestimate the peak deflections at midday: on July $11^{\text {th }}$ there is up to $64 \mathrm{~mm}$ of error between the vertical deflection data sets. This is partly because of errors produced in the temperature results. Additionally these overestimates occur whenever the temperature gradient through the suspended is large. This implies that low truss temperatures require more influence on the simulated thermal movements to better represent the behaviour seen in the monitored results. The thermal expansion relating to the truss temperature is further discussed in a later section of this paper.

The sway of the tower tops was also considered to see if their structural performance coincided with their thermal performance (in Figure 5 bottom) and to see whether the time of peak sway is 4 hours after the peak deck expansion shown previously in Figure 6 . However the results in Figure 7 show little resemblance in the behaviour between the two towers, suggesting that other variables are involved. For instance, the sway of the Plymouth tower (top) in both the monitored and FE results moves west during the morning. The sway displacements typically peak at midday like the deck displacements, rather than midafternoon like the tower temperature time series. This phenomenon is linked to the longitudinal movement of the suspended structure towards the expansion gap at the Saltash tower. As the deck moves outwards, the stay cables pull the Plymouth tower towards midspan. 

opposite direction of the Plymouth tower. The displacement at the Saltash tower's top are not as large as at Plymouth, so the Saltash tower is not so affected by the attached stay cables' tensions. The behaviour of the tower also shows little association with the deck displacements; the mainly irregular line formed from the data suggests a dynamic influence such as traffic and wind.

To summarise, the qualitative observations in the temperature and structural time series suggests behaviours that were either directly linked or were delayed by a few hours. The following sections detail the systematic examinations on the data to identify the collective mechanisms that cause this behaviour, as well as their influence on the relationships.

\section{Relationships found within the bridge behaviour}

\section{Relationship of expansion with temperature}

In order to see how the solar intensity affects the quasi-static configuration of the bridge, Figure 8 plots the FE simulated midspan deflections against the temperature of the deck, suspension cable and the truss. The samples are split into two groups, depending on whether the applied solar intensity was below $50 \mathrm{~W} / \mathrm{m}^{2}$, which is at night or during winter, or above. expansion of the bridge deck at midspan has a linear relationship with temperature, since the temperature differential across the bridge section is small. For data where the applied solar radiation exceeds $50 \mathrm{~W} / \mathrm{m}^{2}$ (top right) the relationship for all three temperature parameters with the deck expansion turns nonlinear. The deck expands further than the truss, and if the cables were not present the supported structure would curve upwards. At this level of solar radiation the temperature differential between the deck and the truss is more pronounced and 
it is more evident that the thermal expansion is a product of two or more parameters. Similar behaviour is observed in the vertical deflections at the mid-span (bottom), except the relationship of the suspended structure sag to the suspension cables' temperature appears to be highly linear.

Analysts may consider adopting an effective temperature as an average of the deck, truss and suspension cable temperatures, but this assumes that all three are equally important for longitudinal and vertical movements. For structural systems like the Tamar Bridge this may not be the case. While the orthotropic deck is wide and experiences large fluctuations in diurnal temperature, the stiffness of the suspended structure is mainly provided by the truss, which is warmed by the air underneath the deck. Likewise the suspension cable provides more vertical support to the structure than the deck system.

Considering the various nonlinearities appearing in the data, it seems that mathematical models should attempt to account for all three thermal parameters, revealing their relative influence on bridge response through their coefficients. One approach is response surface modelling, which is similar to regression analyses, by using the least squares method to weight polynomial coefficients linking input parameters to a specific single output. In this case the inputs are the temperature data, and the output is a thermal displacement. This method is straightforward and provides direct interpretation of the physical behaviour of the bridge. Response surface models have been used on the Tamar Bridge before by Cross et al. (2013) to associate a variety of environmental and operational factors with the response of the first mode of vibration.

Fitting a surface to the 60 days of data with longitudinal displacements as the output generates coefficients shown in Table 2 . The coefficients indicate that the longitudinal expansion of the supported structure is more dependent on temperature of the deck and the truss, while other inputs such as the suspension cable temperature have a smaller effect. For 
the vertical deflection, the largest coefficient is associated with the suspension cable temperature. This indicates the rise of the suspended structure is mostly dependent on the thermal response of the suspension cable rather than its own temperature.

Comparing the coefficients between the monitored and simulated data sets, the model for monitored results imply the truss temperature accounts for almost a third of the bridge's expansion, while the thermal response determined by the FE model is mostly determined by the temperature of the deck. Similarly the vertical deflections in the monitored results show more dependency on the truss temperature than the simulated deflections. This was observable in the time series shown previously in Figure 6, where the thermal deflections in simulated results are over estimates of the monitored results. This implies that the FE model needs to be updated so that the truss should have slightly more bearing on the simulated deflections. Modifications to the FE model did not provide a considerable improvement of the results but after several attempts it would seem that either the axial stiffness of the truss may be larger than expected or the connections between the deck and the truss are too stiff. It has also been noted that response surface models based on monitored data differ on a month by month basis, so it is possible that there are changes to the actual structure's configuration due to seasonal behaviour and a single model is insufficient.

\section{Effect of cable temperature on Saltash and Plymouth tower sway}

Figure 9 plots the monitored and FE simulated tower displacements against the suspension cable temperature to check whether their different behaviour is linked to the thermal response of the structure. The monitored deflections of the Saltash tower (top left) do not show a clear linear relationship with the cable temperature due to the irregularity of the Saltash tower deflection time series (Figure 7). The FE results (bottom left) of the Saltash tower show a shallow linear trend with temperature, compared to the trend for the Plymouth tower (top 
right) which is steeper. As stated previously diurnal Saltash tower sway is mostly independent of the bride's thermal response, reacting to wind speeds and vehicle loads instead. However if the points are shading-coded to the time of day they occur a line of black dots appears in the monitored results, which are designated for samples collected between 20:00 and 04:00. This shows that temperature induced deflections on the Saltash tower can be observed from seasonal variations, while during the day other factors govern.

For the Plymouth tower (top right) the linear relationship between temperature and tower sway shows that an increase in cable temperature goes with the Plymouth tower deflecting towards the mid-span. There is some phase difference in the relationship, causing otherwise linear trends to open slightly to form elliptic loops. The underlying linearity indicates that it is mostly the thermal response of the suspended structure and the cables that governs the Plymouth tower sway, rather than the delayed thermal response of the tower.

Points in the monitored results for both towers do not fall perfectly on a single line, unlike the FE results (Figure 9 bottom). The shading-coded points in the top plots demonstrate that the monitored data are made up of several offset 'bands'. The offsets are not due to extended loading such as traffic jams as these cause relatively small deflections, no more than $4 \mathrm{~mm}$. A line in the plots with the monitored results show where samples collected from May 2010 lie. These have a linear relationship but deflections are lower than at other times during the year. This shows that the bands in the plots are seasonal deviations of the monitored displacements caused by the towers reconfiguring over the course of the year, in response to changing tensions in the suspension and stay cables. This may be caused by the position of the sun, since during the summer the sun rises over the top of the bridge, rather than to its south side, and the structural members would be warmed from three of it sides. However, this is only a hypothesis, since the north-south position could not be included in the adopted method for simulating solar radiation. 


\section{Summary and conclusions}

512 This investigation presents monitored thermal induced behaviour observed on the Tamar

513 Bridge taken from five days in each month for a whole year. The mechanisms that cause this

514 behaviour were explored by applying simulated solar radiation effects to a complete FE 515 model of the bridge.

516 The following conclusions have been drawn from this investigation:

517 - Cloud cover information can be reasonably approximated from the relative temperature

518 difference through the deck over a period of a month.

- On most of the examined days, the temperature of the deck was first to reach its peak

520 compared to the rest of the structure, which is due to the asphalt layer and the orthotropic

521 decks slenderness. The suspension cable peaked an hour later, while the concrete towers

522 reached their maximum temperature 4 hours after the deck's maximum temperature, since 523 concrete is more capable of retaining than steel.

- The thermal expansion of the suspended structure is linked to the combined temperature of

525 the deck and the truss, while its sag is dependent on the thermal elongation of the

$526 \quad$ suspension cable.

- The behaviour of the Saltash tower was mostly unrelated to the diurnal thermal behaviour

528 of the bridge, since it is located near the main span expansion gap. However, a seasonal

529 thermal response was observed if only early morning samples were considered.

530 - The sway of the Plymouth tower was linked to the thermal expansion of the deck, which 531 pulled it towards the bridge midspan as the bridge warmed up.

\section{Acknowledgements}

533 Thanks to David List and Richard Cole of Tamar Bridge for their enduring support for the 

and EP/G0611301/1.

\section{Appendix}

\section{A.1 Daily values}

538 The majority of the steps shown here have been duplicated from a paper by Rivington et al. 539 (2005).

Total daily irradiance, $J_{0}$ is given by

$$
D J_{0}=S J_{0, s}+D J_{0, d}
$$

541 where $D$ is the day length, $S$ the sunshine duration, $J_{0, s}$ the direct beam component and

$542 J_{0, d}$ the diffuse component. The day length in hours is calculated by

$$
D=\frac{24}{\pi} \cos ^{-1}(-\tan \lambda \tan \delta)
$$

543 where $\lambda$ is the latitude of the location and $\delta$ the solar declination, both measured in radians.

544 The solar declination for a day in a year may be found by

$$
\delta=-0.4084 \cos \left(2 \pi \frac{d+10}{365}\right)
$$

545 where $d$ is the day of the Year (e.g. $d=1$ for January $1^{\text {st }}$ ).

The direct beam component is given by

$$
J_{0, s}=1367 \frac{2 p}{\pi}\left(\tau^{1 / \sin \varnothing_{0}}\right) \sin \varnothing_{0}
$$

547 where $p$ is the fraction of radiation in full spectrum sunlight (1 has been used, for simplicity), 5481367 is the solar constant (in $\mathrm{W} / \mathrm{m}^{2}$ ), $\tau$ is the atmospheric transmissivity and $\varnothing_{0}$ is the solar 549 elevation at noon, in radians: $\sin \varnothing_{0}$ may be found via 


$$
\sin \varnothing_{0}=\sin \lambda \sin \delta+\cos \lambda \cos \delta
$$

Atmospheric transmissivity, $\tau$, was calculated as a function of the elevation $(v)$ and range of diurnal air temperature values on site ( $\Delta T)$, as provided by Coops et al. (2000),

following a similar model developed by Thornton and Running (1999).

$$
\tau=(0.65+0.008 v) \cdot\left[1-\exp \left(-B \cdot \Delta T^{1.5}\right)\right]
$$

where $v$ is $43.2 \mathrm{~m}$ for Tamar Bridge, and

$$
B=0.031+0.201 \exp (-0.185 \cdot \Delta T)
$$

554

555

556

557

558

559

560

561

562

563

564

565

This is an alternative to the formula used by Woodward et al. (2001), where

atmospheric transmissivity was a function of the day of the year. This was not adopted since the range of monitored air temperatures at Plymouth was similar for the whole observed year, probably due to atypical seasonal cloud cover, and as a result atmospheric transmissivity is affected. Baigorria et al. (2004) has shown that transmissivity models relating to the air temperature demonstrate more reliable results for the Andes compared to models that are dependent on time.

The diffuse portion of total irradiance $J_{0, d}$ can be calculated by

$$
J_{0, d}=J_{0, p}\left(f_{\text {blue }} \cdot\left(1-f_{c c}\right)+f_{\text {cloud }} \cdot f_{\text {cc }}\right)
$$

where $f_{c}$ is the mean daily cloud cover, which is assumed to be $f_{c}=1-(S / h)$, being a dimensionless value between 0 (no cloud cover) and 1 (complete cloud cover).

$J_{0, p}$ is the potential total clear sky mean daily irradiance, which is calculated by

$$
J_{0, p}=1367 \frac{p}{\pi}\left(1+\tau^{1 / \sin \varnothing_{0}}\right) \sin \varnothing_{0}
$$

The values of $f_{\text {blue }}$ and $f_{\text {cloud }}$ are the relative radiation intensities under blue sky and 
cloudy conditions, respectively.

$$
\begin{gathered}
f_{\text {blue }}=\frac{1-\tau^{1 / \sin \varnothing_{0}}}{1+\tau^{1 / \sin \varnothing_{0}}} \\
f_{\text {cloud }}=F \cdot f_{\text {blue }}
\end{gathered}
$$

567

568

569

570

571

572

573

574

575

576

Chen et al. (1999), is

$$
J_{t}=J_{0} \cos \left(\frac{\theta-\theta_{0}}{\pi / 2-\theta_{0}} \cdot \frac{\pi}{2}\right)
$$

577 where $\theta$ is the solar zenith angle and $\theta_{0}$ is the solar zenith angle at solar noon, which is not

578 necessarily at $12: 00 \mathrm{pm}$. This formula is only applicable when $\theta<\pi / 2$, otherwise the sun 579

580

581

582

583

varies between 0.69 and 0.87 . For the purposes of this study a value of 0.884 was taken,

which is the value found at Aberporth; the closest available site being $195 \mathrm{~km}$ away from Plymouth (Miller et al. 2008).

\section{A.2 Half-hourly values}

Following the identification of total daily irradiance, the next step is to identify the amount of radiation upon the bridge in half-hourly steps. The daily course of the sun takes a cosine pattern; providing 0 radiation between dusk and the dawn of the following day, and reaches its peak at solar noon. Thus the hourly dependent formula for solar radiation, $J_{t}$, taken from will be beyond the horizon; hence no sunlight!

\section{A.3 Factor for inclined surfaces}

If the surface is inclined, such as on the towers, it is likely that it will be within its own shade when the sun is on its opposite side. Thus the direct beam component in Equation (A.4) has to be adjusted (Sellers et al. 1997; Wang et al. 2002): 


$$
J_{0, s, i}=f_{i} \cdot J_{0, s}
$$

584 where $f_{i}$ is the direct beam correction factor, which is limited to values between 0 and 1 .

585 This value is dependent on the angle of the slope and the solar zenith angle $\theta$ :

$$
f_{i}=\frac{\cos \theta_{i}}{\cos \theta}
$$

586

587

588 zero, East $\left.=90^{\circ}\right)$, the solar zenith angle and the solar azimuth $\psi\left(\right.$ North $=$ zero, East $=90^{\circ}$.

$$
\cos \theta_{i}=\cos \beta \cos \theta+\sin \beta \sin \theta \cos (\psi-\gamma)
$$

where $\theta_{i}$ is the angle between the solar zenith angle to the slope normal, which is determined from the inclination from the horizontal for the slope $\beta$, the aspect of the face $\gamma$ (North $=$
589

590

591

592

593

594

595

596

597

598

599

600

601

602 
603

604

605

606

607

608

609

610

611

612

613

614

615

616

617

618

619

620

621

622

623 624 625

626

Cao, Y., Yim, J., Yang, Z., and Wang, M. L. (2010). “Temperature effects on cable stayed bridge using health monitoring system: a case study." Structural Health Monitoring, $10(5), 523-537$.

Chen, J. M., Liu, J., Cihlar, J., and Goulden, M. L. (1999). “Daily canopy photosynthesis model through temporal and spatial scaling for remote sensing applications." Ecological modelling, Elsevier, 124(2-3), 99-119.

Churchward, A., and Sokal, Y. J. (1981). "Prediction of Temperatures in Concrete Bridges." Journal of the Structural Division, 107(11), 2163-2176.

Comité Euro-International du Béton. (1993). CEB-FIP Model Code 1990: Design Code. Thomas Telford Limited, 61-66.

Coops, N. C., Waring, R. H., and Moncrieff, J. B. (2000). “Estimating mean monthly incident solar radiation on horizontal and inclined slopes from mean monthly temperatures extremes.” International Journal of Biometeorology, Springer Berlin / Heidelberg, 44(4), 204-211.

Cross, E., Koo, K. Y., Brownjohn, J. M. W., and Worden, K. (2013). “Long-term monitoring and data analysis of the Tamar Bridge.” Mechanical Systems and Signal Processing, $35(1-2), 16-34$.

Cross, E., Worden, K., Koo, K.-Y., and Brownjohn, J. M. W. (2011). “Co-integration and SHM of bridges." 8th International Workshop on Structural Health Monitoring, Stanford, California.

Ding, Y.-L., and Li, A. (2011a). “Temperature-induced variations of measured modal frequencies of steel box girder for a long-span suspension bridge." International Journal of Steel Structures, Korean Society of Steel Construction, co-published with Springer, $11(2), 145-155$. 
Ding, Y.-L., and Li, A. (2011b). “Assessment of bridge expansion joints using long-term displacement measurement under changing environmental conditions.” Frontiers of Architecture and Civil Engineering in China, Higher Education Press, co-published with Springer-Verlag GmbH, 5(3), 374-380.

Elbadry, M. M., and Ghali, A. (1983). “Temperature variations in concrete Bridges.” Journal of Structural Engineering, 109(10), 2355-2374.

Hirst, M. J. S. (1984). “Thermal loading of concrete bridges.” Canadian Journal of Civil Engineering, NRC Research Press Ottawa, Canada, 11(3), 423-429.

Ho, D., and Liu, C.-H. (1989). “Extreme Thermal Loadings in Highway Bridges.” Journal of Structural Engineering, 115(7), 1681-1696.

Johnson, I. R., Riha, S. J., and Wilks, D. S. (1995). "Modelling daily net canopy photosynthesis and its adaptation to irradiance and atmospheric CO2 concentration." Agricultural Systems, Elsevier, 50(1), 1-35.

Koo, K. Y., Brownjohn, J. M. W., List, D. I., and Cole, R. (2012). "Structural health monitoring of the Tamar suspension bridge." Structural Control and Health Monitoring, 20(4), 609-625.

Koo, K.-Y., de Battista, N., and Brownjohn, J. M. W. (2011). "SHM data management system using MySQL databse with MATLAB and Web interfaces." Proceedings of the 5th International Conference on Structural Health Monitoring of Intelligent Infrastructure (SHMII-5), Cancun, Mexico, 1-9.

Koo, K.-Y., Brownjohn, J. M. W., List, D., Cole, R., and Wood, T. (2010). "Innovative Structural Health Monitoring for Tamar Suspension Bridge by Automated Total Positioning System." Proceedings of the 7th International Conference on Bridge Maintenance, Safety and Management (IABMAS), 1-8. 
Liu, C., DeWolf, J. T., and Kim, J.-H. (2009). "Development of a baseline for structural health monitoring for a curved post-tensioned concrete box-girder bridge.” Engineering Structures, 31(12), 3107-3115.

Liu, H., Chen, Z., and Zhou, T. (2012). "Theoretical and experimental study on the temperature distribution of $\mathrm{H}$-shaped steel members under solar radiation.” Applied Thermal Engineering, 37, 329-335.

Miao, C.-Q., Chen, L., and Feng, Z.-X. (2011). "Research on correlation of modal frequency of long-span bridge structures and environmental temperature.” 2011 International Conference on Multimedia Technology, IEEE, Hangzhou, 1175-1179.

Miller, D. G., Rivington, M., Matthews, K. B., Buchan, K., and Bellocchi, G. (2008). "Testing the spatial applicability of the Johnson-Woodward method for estimating solar radiation from sunshine duration data." Agricultural and forest meteorology, Elsevier, $148(3), 466-480$.

Minhoto, M. J. C., Pais, J. C., Pereira, P. A. A., and Picado-Santos, L. G. (2005). “Predicting asphalt pavement temperature with a three-dimensional Finite Element method." Transportation Research Record: Journal of the Transportation Research Board, 1919, 96-110.

Moorty, S., and Roeder, C. W. (1992). “Temperature-Dependent Bridge Movements.” Journal of Structural Engineering, 118(4), 1090-1105.

Ni, Y. Q., Hua, X. G., Wong, K.-Y., and Ko, J. M. (2007). “Assessment of Bridge Expansion Joints Using Long-Term Displacement and Temperature Measurement.” Journal of Performance of Constructed Facilities, 21(2), 143-151.

Peeters, B., and De Roeck, G. (2001). “One-year monitoring of the Z24-Bridge: environmental effects versus damage events." Earthquake Engineering \& Structural Dynamics, 30(2), 149-171. 
676 Rivington, M., Bellocchi, G., Matthews, K. B., and Buchan, K. (2005). "Evaluation of three

677

678

679

680

681

682

683

684

685

686

687

688

689

690

691

692

693

694

695

696

697

698

699

700

model estimations of solar radiation at 24 UK stations." Agricultural and forest meteorology, Elsevier, 132(3-4), 228-243.

Sellers, P. J., Heiser, M. D., Hall, F. G., Verma, S. B., Desjardins, R. L., Schuepp, P. M., and MacPherson, J. I. (1997). "The impact of using area-averaged land surface propertiestopography, vegetation condition, soil wetness - in calculations of intermediate scale (approximately $10 \mathrm{~km} 2$ ) surface-atmosphere heat and moisture fluxes." Journal of Hydrology, 190(3-4), 269-301.

Sohn, H. (2007). "Effects of environmental and operational variability on structural health monitoring." Philosophical transactions. Series A, Mathematical, physical, and engineering sciences, 365(1851), 539-60.

Thornton, P. E., and Running, S. W. (1999). “An improved algorithm for estimating incident daily solar radiation from measurements of temperature, humidity, and precipitation.” Agricultural and Forest Meteorology, 93(4), 211-228.

Tong, M., Tham, L. G., and Au, F. T. K. (2002). "Extreme thermal loading on steel bridges in tropical region.” Journal of Bridge Engineering, 7(6), 357-366.

Tong, M., Tham, L. G., Au, F. T. K., and Lee, P. K. K. (2001). "Numerical modelling for temperature distribution in steel bridges." Computers and Structures, Elsevier, 79(6), $583-593$.

Wang, S., Chen, W., and Cihlar, J. (2002). "New calculation methods of diurnal distribution of solar radiation and its interception by canopy over complex terrain.” Ecological Modelling, 155(2-3), 191-204.

Westgate, R. J., and Brownjohn, J. M. W. (2010). "Development of a Tamar Bridge Finite Element Model.” Proceedings of IMAC XXVIII, Springer New York, Jacksonville, FL, USA. 
Woodward, S. J. R., Barker, D. J., and Zyskowski, R. F. (2001). “A practical model for predicting soil water deficit in New Zealand pastures.” New Zealand Journal of Agricultural Research, Taylor \& Francis, 44(1), 91-109.

Xia, Y., Chen, B., Zhou, X., and Xu, Y. L. (2013). "Field monitoring and numerical analysis of Tsing Ma Suspension Bridge temperature behavior." Structural Control and Health Monitoring, 20(4), 560-575.

Xia, Y., Xu, Y. L., Wei, Z. L., Zhu, H. P., and Zhou, X. Q. (2011)."Variation of structural vibration characteristics versus non-uniform temperature distribution.” Engineering Structures, 33, 146-153.

Xu, Y. L., Chen, B., Ng, C. L., Wong, K.-Y., and Chan, W. Y. (2010). "Monitoring temperature effect on a long suspension bridge." Structural Control and Health Monitoring, 17, 632-652.

Zhou, H. F., Ni, Y. Q., and Ko, J. M. (2010). “Constructing input to neural networks for modeling temperature-caused modal variability: Mean temperatures, effective temperatures, and principal components of temperatures." Engineering Structures, 32(6), 1747-1759. 
Click here to download Table: t_1.docx

Table 1: Typical heat transfer properties

\begin{tabular}{|c|c|c|c|c|c|}
\hline \multirow[t]{2}{*}{ Property } & \multicolumn{2}{|c|}{ Suspension cable } & Bridge deck & \multicolumn{2}{|l|}{ Towers } \\
\hline & (a) $-20^{\circ} \mathrm{C}$ & @ $100^{\circ} \mathrm{C}$ & $@-20^{\circ} \mathrm{C} @ 100^{\circ} \mathrm{C}$ & @ - $20^{\circ} \mathrm{C}$ & @ $100^{\circ} \mathrm{C}$ \\
\hline $\begin{array}{l}k, \text { thermal } \\
\text { conductivity }\left(\mathrm{W} / \mathrm{m}^{\circ} \mathrm{C}\right)\end{array}$ & 54.7 & 50.7 & 2.5 & 1.71 & 1.50 \\
\hline $\begin{array}{l}c, \text { heat capacity } \\
\left(\mathrm{J} / \mathrm{kg}^{\circ} \mathrm{C}\right)\end{array}$ & 416 & 488 & 680 & & 00 \\
\hline $\begin{array}{l}h, \text { convection } \\
\text { coefficient }\left(\mathrm{W} / \mathrm{m}^{2 \circ} \mathrm{C}\right)\end{array}$ & \multicolumn{2}{|c|}{18.5} & 26 & \multicolumn{2}{|c|}{25} \\
\hline $\begin{array}{l}\varepsilon, \\
\text { emissivity } \\
\text { coefficient }\end{array}$ & \multicolumn{2}{|c|}{0.8} & 0.9 & \multicolumn{2}{|c|}{0.7} \\
\hline $\begin{array}{l}\alpha, \text { absorption } \\
\text { coefficient }\end{array}$ & \multicolumn{2}{|c|}{0.75} & 0.9 & \multicolumn{2}{|c|}{0.65} \\
\hline
\end{tabular}


Click here to download Table: t_2.docx

Table 2: Coefficients determined from response surface models predicting bridge displacements at midspan.

\begin{tabular}{llll}
\hline \hline & $\begin{array}{l}\text { Temperature } \\
\text { variable }\end{array}$ & $\begin{array}{l}\text { Coefficient } \\
\text { with FE simulated } \\
\text { data }\end{array}$ & $\begin{array}{l}\text { with monitored } \\
\text { data }\end{array}$ \\
\hline Longitudinal & Deck & $+3.00 \mathrm{~mm} /{ }^{\circ} \mathrm{C}$ & $+2.05 \mathrm{~mm} /{ }^{\circ} \mathrm{C}$ \\
& Truss & $+0.26 \mathrm{~mm} /{ }^{\circ} \mathrm{C}$ & $+1.33 \mathrm{~mm} /{ }^{\circ} \mathrm{C}$ \\
\hline Vertical & Deck & $-1.53 \mathrm{~mm} /{ }^{\circ} \mathrm{C}$ & $-1.12 \mathrm{~mm} /{ }^{\circ} \mathrm{C}$ \\
& Cable & $-10.80 \mathrm{~mm} /{ }^{\circ} \mathrm{C}$ & $-5.51 \mathrm{~mm} /{ }^{\circ} \mathrm{C}$ \\
& Truss & $+0.44 \mathrm{~mm} /{ }^{\circ} \mathrm{C}$ & $-3.45 \mathrm{~mm} /{ }^{\circ} \mathrm{C}$ \\
\hline \hline
\end{tabular}




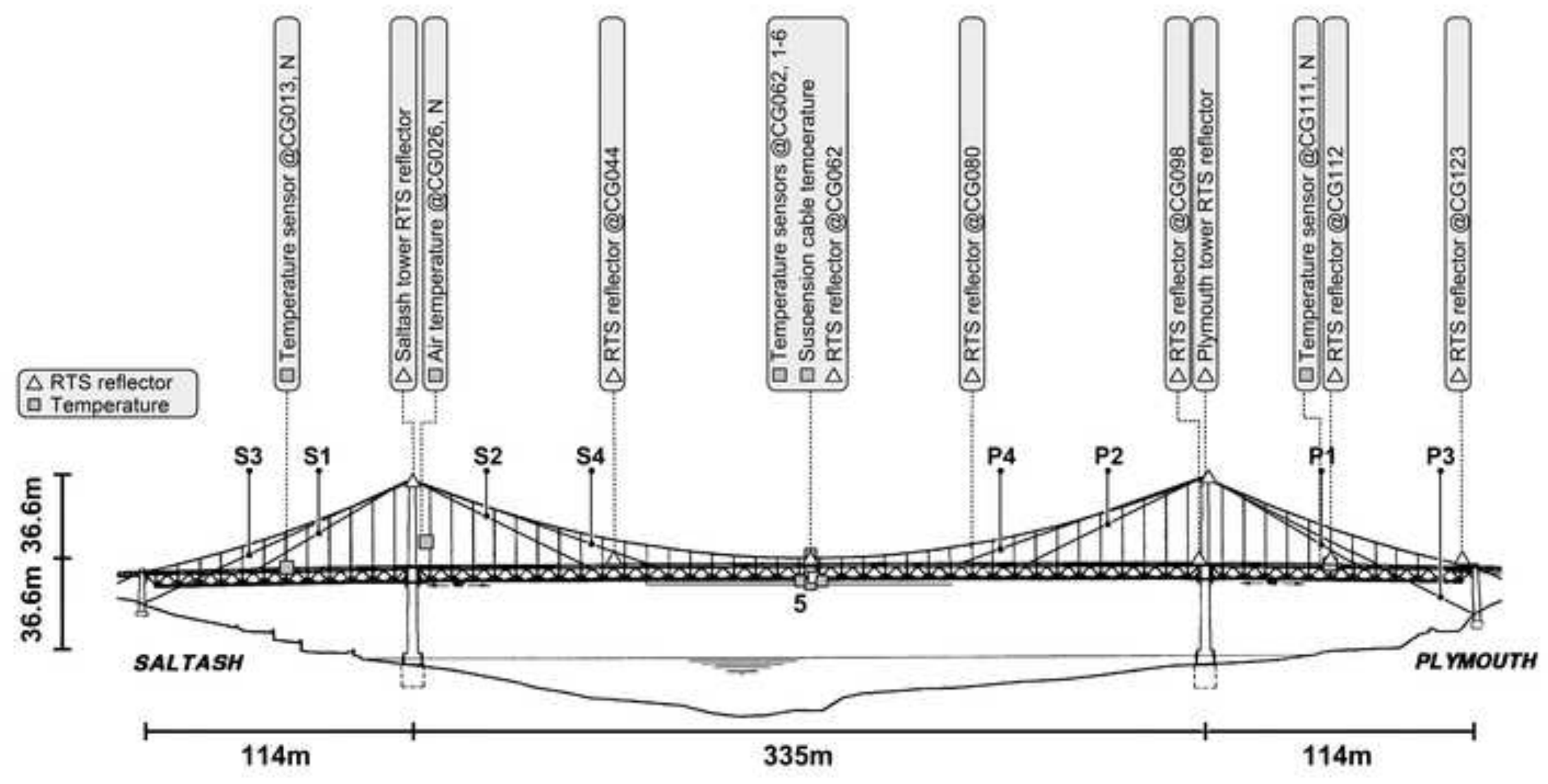


Figure 2
Click here to download Figure: $f \_2 b . e p s$

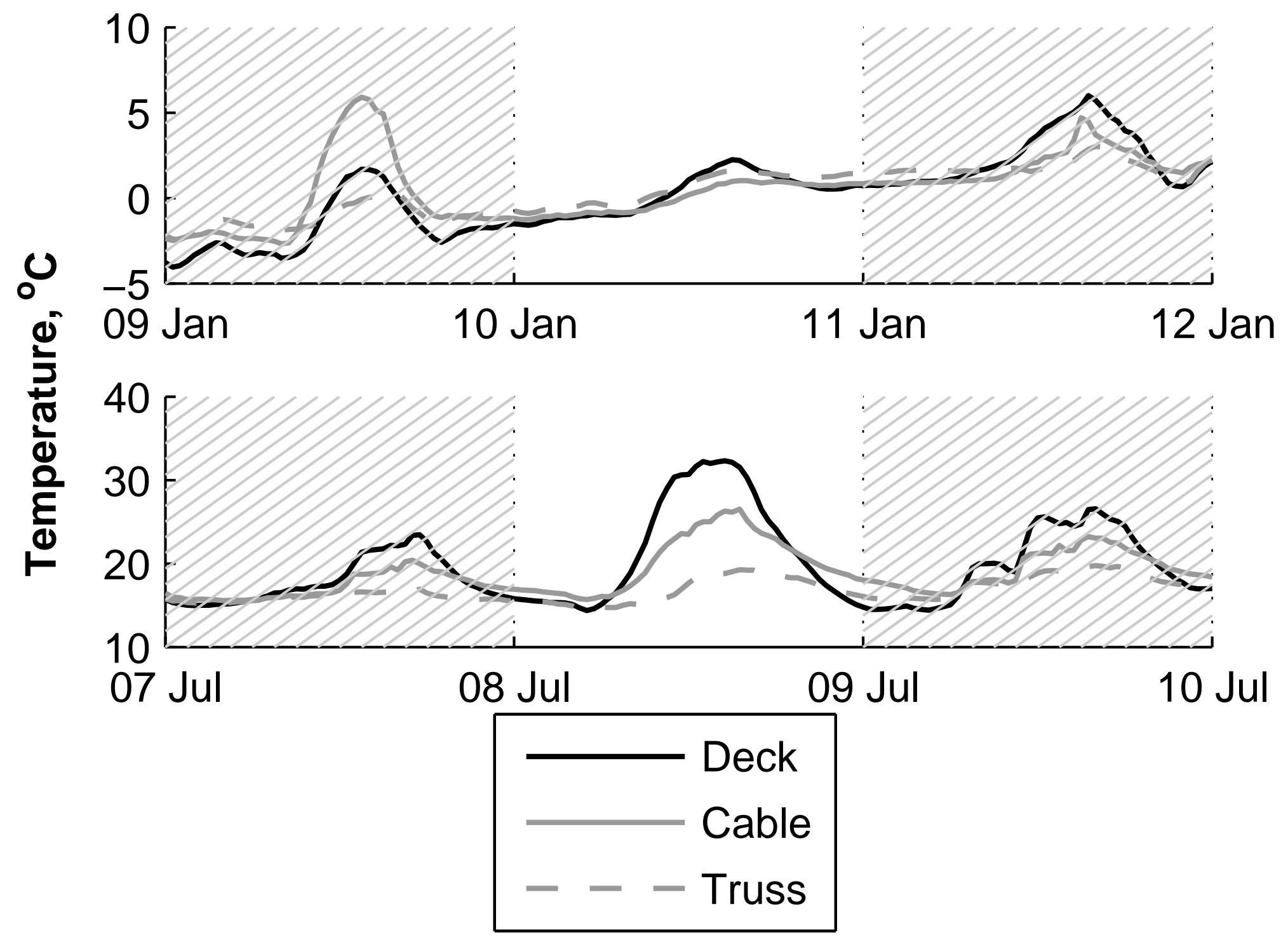




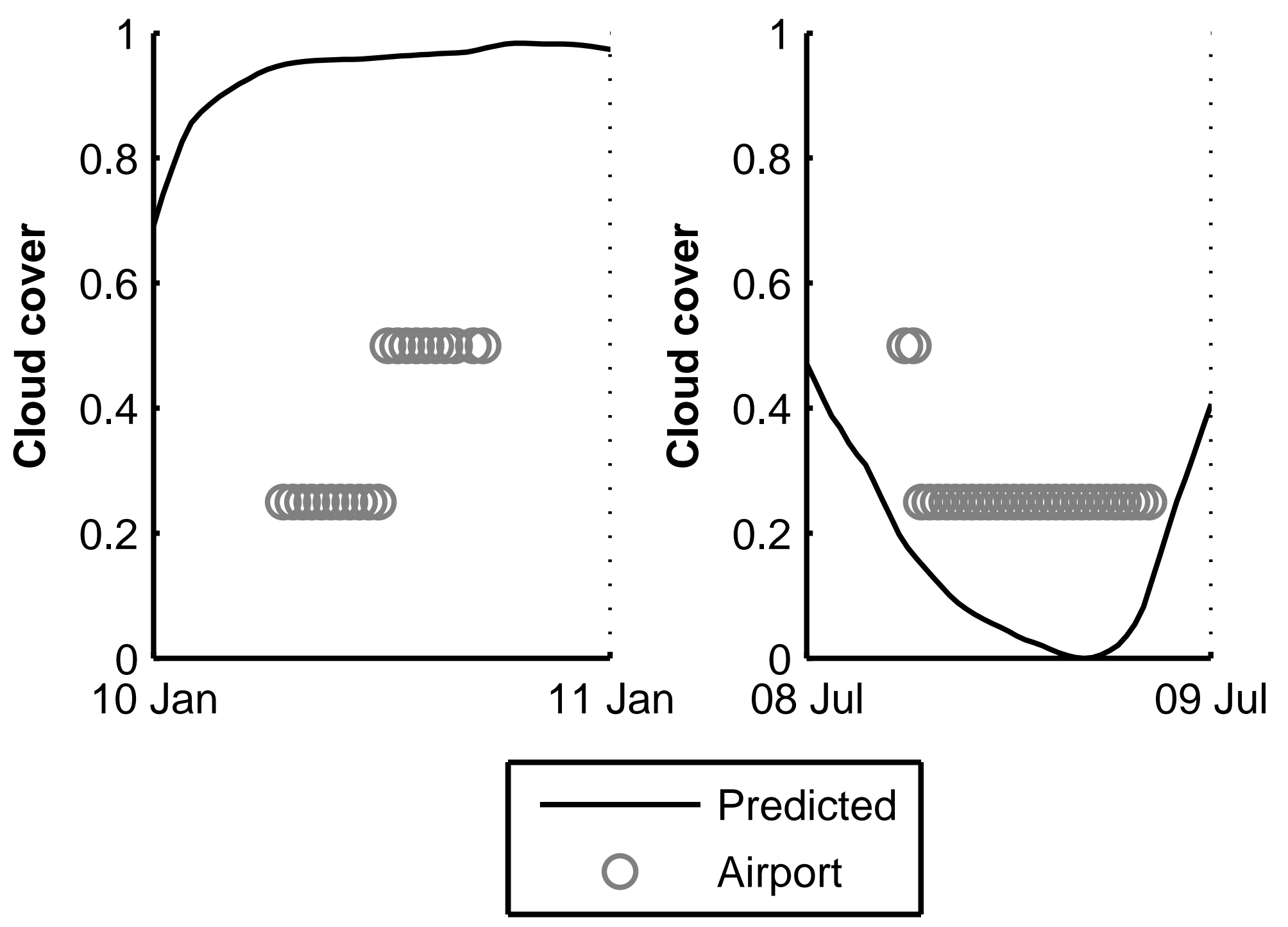




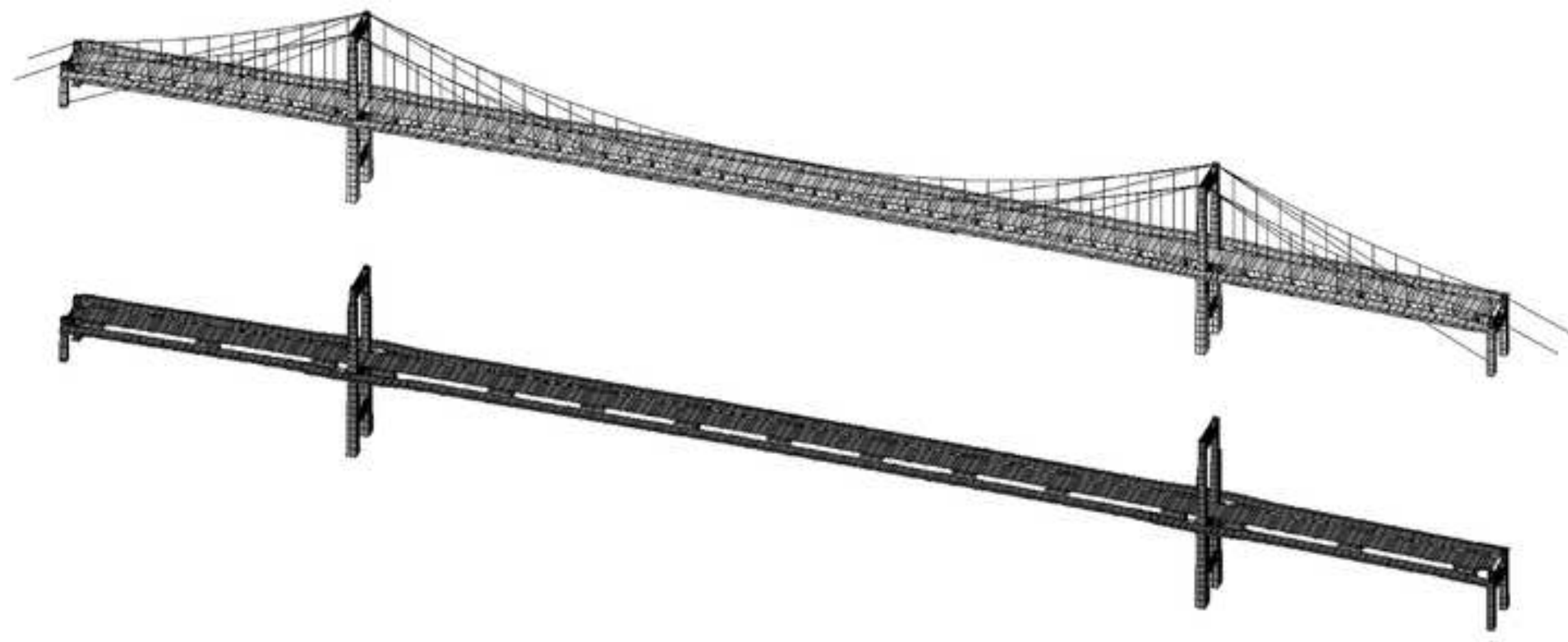


Click here to download Figure: f_5bJüfy
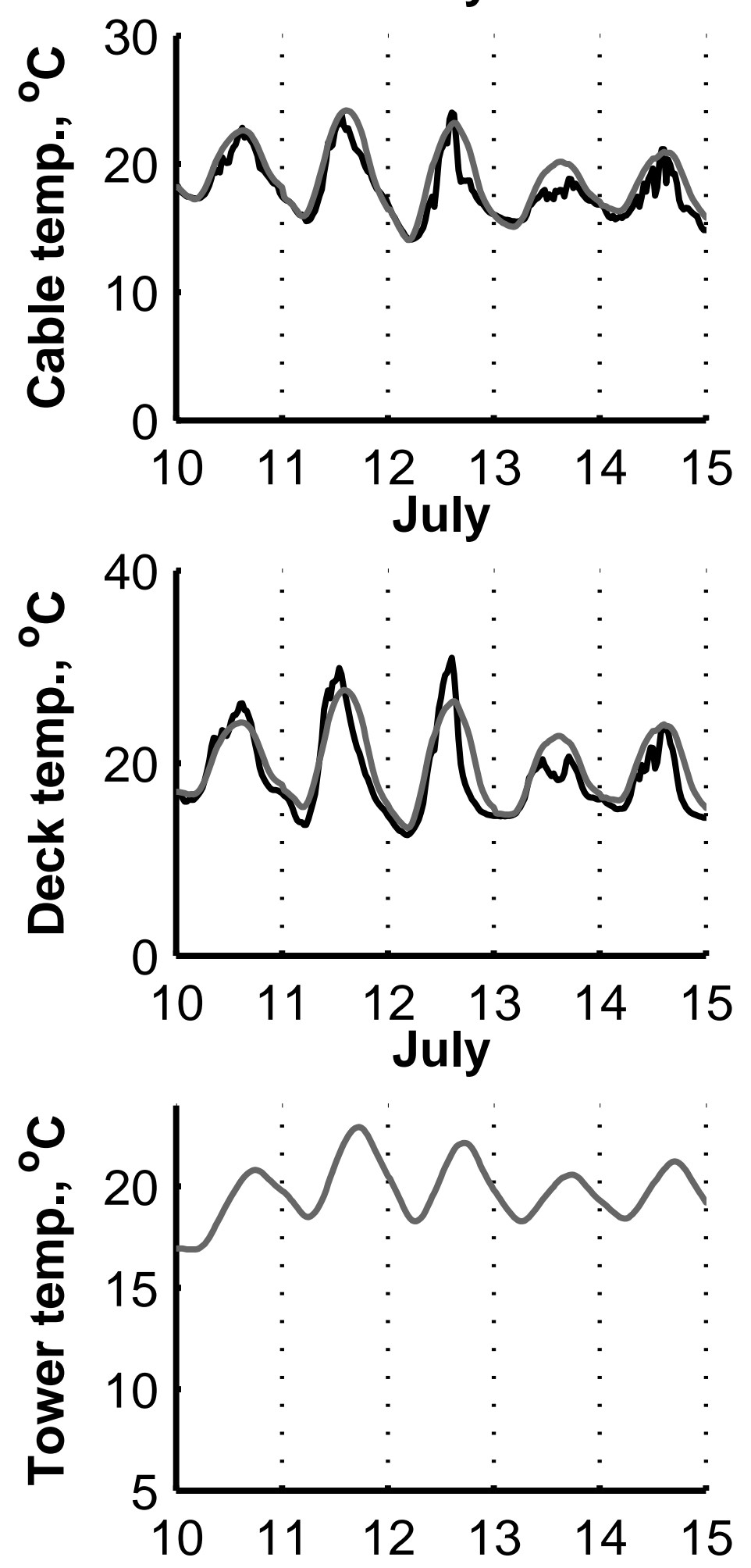

October
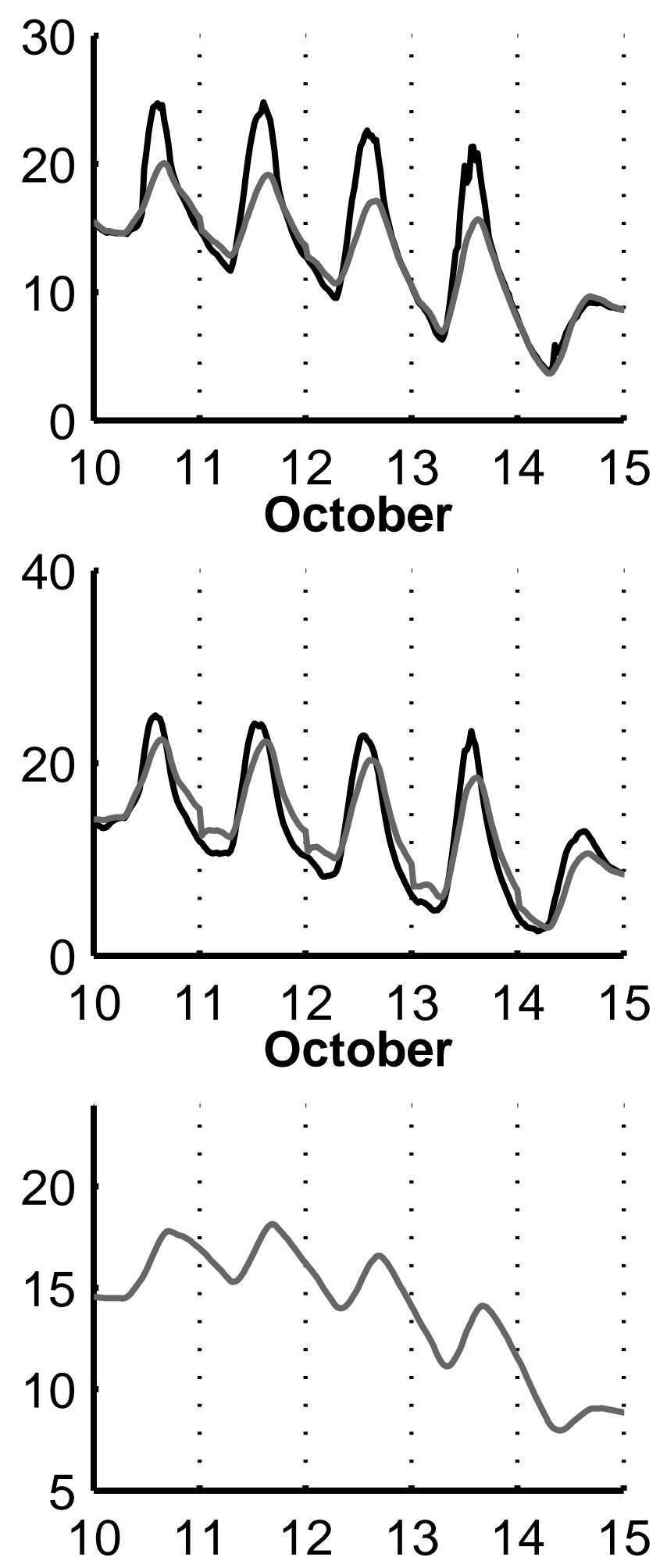

\section{Monitored FE}



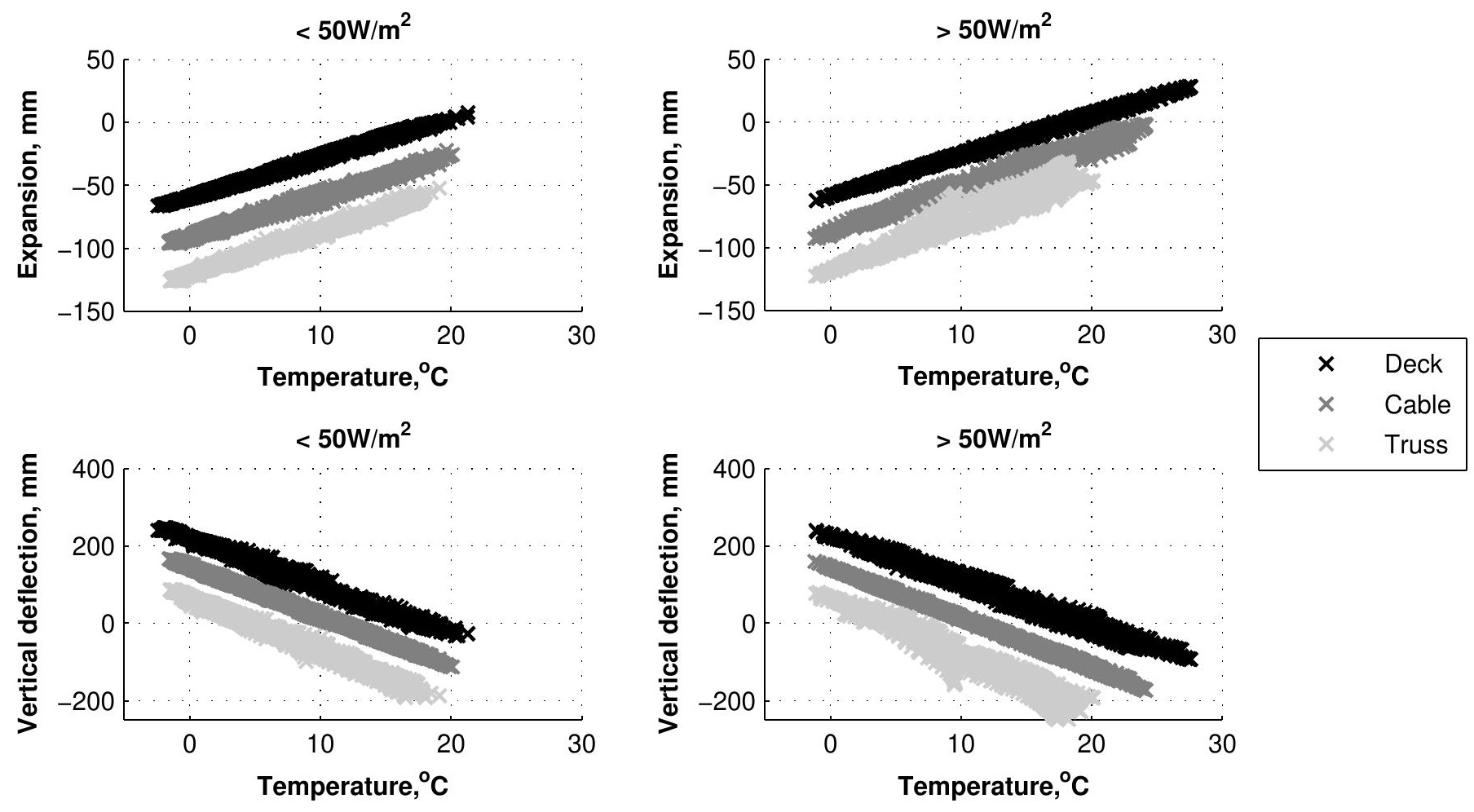


\section{Figure 9}

Click here to download Figure: f_9b.eps
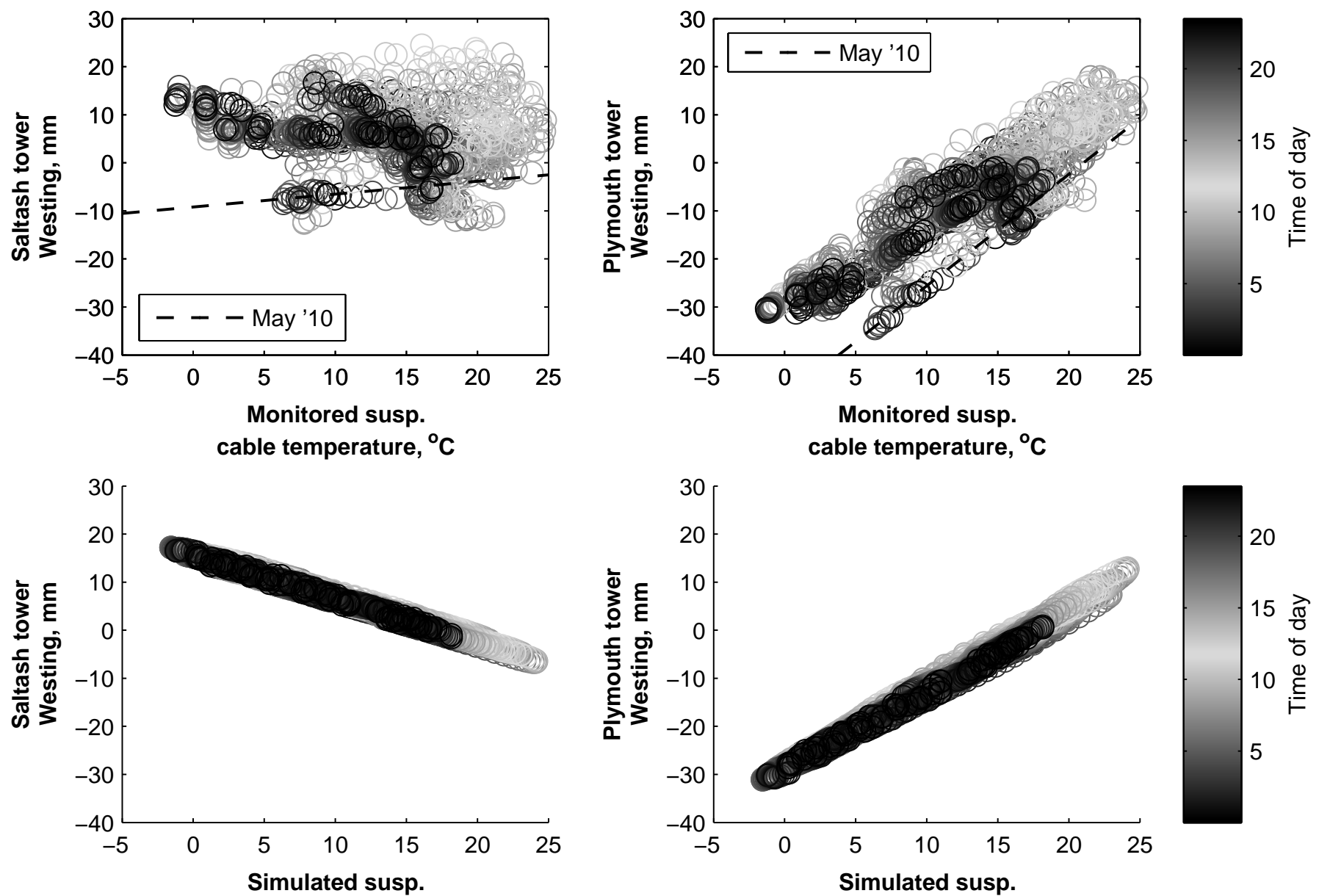
cable temperature, ${ }^{\circ} \mathrm{C}$ cable temperature, ${ }^{\circ} \mathrm{C}$ 


\section{Figure and Table captions}

Figure 1: Dimensions, stay cable layout and sensor layout for Tamar Bridge.

Figure 2: Monitored temperature time series, centred on two dates. Top: January $10^{\text {th }} 2010$ (cloudy sky). Bottom: July $8^{\text {th }} 2010$ (clear sky)

Figure 3: Comparison between airport-monitored and predicted cloud cover

Figure 4: Finite Element model of Tamar Bridge. Top: Structural and thermal conduction elements. Bottom: Solar radiation and convection elements.

Figure 5: Monitored and simulated bridge temperature time series. Top left: Cable temperature in July. Top Right: Cable temperature in October. Middle left: Deck temperature in July. Middle right: Deck temperature in October. Bottom left: Tower temperature in July. Middle right: Tower temperature in October.

Figure 6: Monitored and simulated time series for bridge displacements at midspan. Top left: Longitudinal expansion in July. Top Right: Longitudinal expansion in October. Bottom left: Vertical deflection in July. Bottom right: Vertical deflection in October.

Figure 7: Monitored and simulated time series for spanwise sway of the tops of the main towers (positive values move West). Top left: Plymouth tower in July. Top Right: Plymouth tower in October. Bottom left: Saltash tower in July. Bottom right: Saltash tower in October

Figure 8: Simulated deflections at mid-span (CG062) vs. Temperatures from FE model, separated by levels of solar radiation. Top left: Spanwise expansion on samples below $50 \mathrm{~W} / \mathrm{m}^{2}$. Top right: Spanwise expansion on samples above $50 \mathrm{~W} / \mathrm{m}^{2}$. Bottom left: Vertical deflection on samples below $50 \mathrm{~W} / \mathrm{m}^{2}$. Bottom right: Vertical deflection on samples above $50 \mathrm{~W} / \mathrm{m}^{2}$.

Figure 9: Time dependence of tower deflection vs. Suspension cable temperature. Top row: Monitored. Bottom row: FE Simulated. Left column: Saltash tower. Right column: Plymouth tower.

Table 1: Typical heat transfer properties

Table 2: Coefficients determined from response surface models predicting bridge displacements at midspan. 